\title{
CDKN2C Gene Mutation
}

National Cancer Institute

\section{Source}

National Cancer Institute. CDKN2C Gene Mutation. NCI Thesaurus. Code C41613.

A change in the nucleotide sequence of the CDKN2C gene. 